\title{
The Introduction of the Flexible Zone Programs in the Greek Educational System: Teachers' Perspectives
}

\author{
Vasiliki Brinia $^{1, *}$ and Vasiliki-Nektaria Sarantopoulou ${ }^{2}$ \\ 1 Teacher Education Program, Athens University of Economics and Business, 10434 Athens, Greece \\ 2 School of Humanities, Hellenic Open University, 26335 Patras, Greece; saradvas@yahoo.gr \\ * Correspondence: vbrinia@aueb.gr
}

Received: 25 March 2019; Accepted: 15 May 2019; Published: 20 May 2019

\begin{abstract}
The present paper aims at presenting the introduction of the Flexible Zone program in the context of the Greek Educational system, an innovative, modern teaching program. More specifically, Greek teachers' views on the implementation process, the legislative framework, and the roles of the school head teacher and the school counselor, as well as the difficulties tackled regarding the Flexible Zone programs are thoroughly explored through this study. In order to investigate and better interpret the findings, quantitative research was adopted with questionnaires from 135 teachers having been collected, numbered, coded, and analyzed. Topics such as the importance of in-school seminars and training sessions related to Flexible Zone programs, the significance of the head teacher, school counselor, and the school activities supervisor's contribution, the development of the school equipment and infrastructure, as well as the overall cooperation have emerged from the findings. The present study can offer valuable insights regarding the innovative program of Flexible Zone to the international academic community and policy makers.
\end{abstract}

Keywords: Flexible Zone programs; innovative methods in teaching; Discovery Learning; interdisciplinary approach

\section{Introduction}

\subsection{The Importance and Implementation of International Innovative Programs}

International progress, the rapid development of science and technology acting as external pressure levers, have brought about changes in the field of education. The educational system's decision-makers, to tackle the new order of things, have embraced novelties, because in the existing institutionalized school framework anything that changes constitutes a shift in education [1].

The course for successful, smooth accessibility to the change of the educational system and in particular the school unit, up to the implementation of innovation, consists of three stages: introduction, implementation, and internalization [2]. Initially, the theoretical conceptualization of innovation, the designing of its characteristics on the map, and the clear definition of the role of all participants take place, and then it is all implemented in a pilot phase. The planned change is then tested in selected schools. Early implementation requires the support of the school staff members, namely in the role of the manager, and the scientific, psychological, and technological support of the teachers, to implement the action plan. Progress and problems are monitored, and if everything goes well, there is continuation and spread of innovation. Finally, with the generalized implementation, in the internalization phase, change is no longer considered new and is incorporated into the ordinary way of working in the school, with continuous assessment [3]. In addition, the decentralized, bottom-up approach could be considered as indicative for the implementation of innovative educational programs, in order for each 
school unit to be able to adjust to and maintain the highest quality standards according to the local needs [4].

According to Kirkland and Sutch (2009) [5] an educational innovation is determined by interdependent factors concerning: innovation, (i.e., its pedagogical and technical characteristics), the micro-level (i.e., the teachers' willingness and their competence to act innovatively having specialized knowledge and skills), the middle level (i.e., the social status of the school unit, the local support structures, the school infrastructure) and the macro-level (i.e., the national and supranational policy). Fullan (1988) [6] agrees with the aforementioned view as a guarantee for the successful implementation of innovation, its features, local society, school, and external factors.

At the school's micro-level, according to the new standards, the pillars of innovation are:

(i) individuals, namely human resources, educational staff and their already formed perceptions, focusing on knowledge, skills and attitudes about self-improvement, initiative, and creativity;

(ii) the environment, the developed school culture, the existence of a common vision;

(iii) the supportive institutions and the procedures, in this case the school counselor and

(iv) leadership; the head teacher with a clear vision of the evolution of the school [7] with a position to form an internal educational policy on the basis of the already designed central policies. In this way, the school unit acquires a relative degree of autonomy within the strict administrative nature of the educational system [8]. In educational reality, as a result, teachers and head teachers have the role of the agent of change $[9,10]$.

In addition, through educational programs, teachers are taught by innovative pedagogical practices [11], where, according to Giolitto and Clary (1994) [12] and Gough (1997) [13], experiment with practical innovations. Therefore, these adopted methods cultivate a collaborative spirit at a global level and a spirit of independence in the way that the student chooses the way to learn [14].

\subsection{The Importance and Implementation of the Flexible Zone Programs in Greece}

According to Charlot and Beillerot (1995) [15] and Fullan (1991) [2], innovations are often formulated in programs centered on three areas: (a) changing attitudes and beliefs; (b) implementing new teaching methods; and (c) the use of new teaching tools. The same practice applies to the Greek Educational system as well. In Greece, the innovative educational programs that are being hesitantly implemented are Environmental Education (E.E), Health Education (H.E), European Programs (E.P), Cultural Programs (C.P), Traffic education (T.E), and Consumer Education (C.E), as optional programs. Previous training programs, such as the abovementioned, have prepared suitable ground for the Flexible Zone as a compulsory program. The "Flexible Zone of Inter-Curricular and Creative Activities" or "Flexible Zone" in short, is an innovative educational program, which is utilized in some of the mandatory scheduled hours of the school calendar. In these hours, the purpose of the program is to arm the teachers with the time and institutional framework so that their class can study subjects that appeal to the students themselves, that otherwise would be difficult to focus on during the conventional schedule. Thus, the students feel safe and do not have to worry about their performance, since there is no official grading. The Flexible Zone is characterized as a long-range innovation that, according to Matsagouras (2002b) [16], concerns the whole school system and provides the basis for a wider educational reform, aiming at a triple purpose:

- First, to balance the inelasticity, one-sidedness, and fragmentation of the traditional school system, the result of which promotes experimentation, differentiation, creativity, initiative, and imagination for both teachers and students. That, according to Erickson (1998) [17] leads to a multilevel knowledge and critical treatment of concepts.

- Second, to give the teachers the means (officially allocated time, resources) in order to study subjects that stem from personal interests and the current state of society. Many of these subjects are often thought to be necessities in the modern world, but are not considered crucial or probable enough to occupy their own spots in the mandatory school schedule. 
- Third, and maybe most importantly, to gradually establish through its methods, a refreshing dynamic of principles and ideas, that will change all the aspects of the school life from within.

The Flexible Zone was introduced at a pilot stage by the Ministry of Education and Religious Affairs, through the Pedagogical Institute. The Pedagogical Institute of Greece is the oldest research and consulting institution in education matters, with its work being paramount in setting school policies. Its main purpose is to study the Greek educational system from all angles, to provide suggestions and mandates of all things education-related to the Minister of Education, and also to apply the ministry's decisions at an educational-pedagogical level. The Pedagogical Institute (PI), in order to support teachers who implement work plans in the framework of the Flexible Zone (F.Z.), proposes a range of material for them. Classification of work plans based on their length separates them into short (2 to 5 hours), medium ( 1 or more weeks), and long term ( 2 or more months).

A similar innovative program widely implemented in the U.K. and the United States of America is the "Exploratory Classes or Exploratory Time", where, during a specific hour in the school day, the students are able to explore subjects outside the regular curriculum that may interest them. The students are free to choose among a vast variety of courses, such as Nature Study, Audio-Visual Training, Journalism, Model Making, Drama, Art, and Indian Lore [18]. This stimulates the students to research these subjects on their own, and as a result promotes Discovery Learning [19]. It is important to compare similar programs in order to gain international insights about similar cases and consider the Greek example as a benchmark for international utilization.

Modern pedagogical science, with regard to teaching practice, is based on seven main principles: child-centric approach, supervision, self-activity, teamwork, linking school and life, interdisciplinary, and interpersonal relationships. The project method serves these principles [20] which, according to Patsalis and Papoutsaki (2011) [21], revealed that teachers use it as one of the modern teaching methods in the F.Z. programs while a small percentage $(19.4 \%)$ approached them in an interdisciplinary fashion. However, according to West-Burnham (1995) [22], the conservatism of teachers is a problematic element, who, even if they accept innovation, integrate it into working models and traditional ways of teaching, with Papageorgiou and Tsinas (2010) [23] having showed this in their research. The Project method, according to Frey (1986) [24], is structured in five stages: (i) student initiative to find a topic to be discussed; (ii) exchange of views on the subject; (iii) drawing up a project involving all students and teachers; and (v) completing the project with in-between information and feedback breaks.

\subsection{The Role of Educational Staff in the Implementation of F.Z. Programs}

In order for an educational innovation, such as the F.Z., to be considered successful in its implementation, it initially needs a direct channel to the educational sector, which in this case is the head teacher of each school. First of all, it is necessary for them to be aware of the upcoming innovation and its importance, in order to make their colleagues aware of its value, using dialogue, supportiveness [25], and persuasion as "tools" [26].

Rashid, Hussain, and Nadeem (2011) note that the role of the school head teachers is aligned with innovation, since it encourages teacher creativity and freedom in the classroom by interfering with strengthening, guiding, facilitating, and setting up regulations on a horizontal basis [27]. These are accepted by their colleagues, conditions that promote and support the realization of innovation. In addition, according to Click (2005) [28], head teachers have to encourage school teachers to improve their cognitive level, to test new ideas [29] and skills, to improve their work by using counseling [30], and using the informative role as a tool [31]. The leader (head teacher) directly affects a group of individuals to achieve their team goals [32,33]. It has been shown that participatory management reported by Vroom and Yetton (1973) [34] and the exercise of transformational leadership [35] leads to effective decision making as teachers consider the decisions as their own [36]. Building a cooperative school culture from leadership and sharing power on a wider scale, according to Leithwood, Harris, and Hopkins (2008) [37] are well-suited to establishing change [38]. 
The institution of the supervisor responsible for school activities (as an external advisor) is a stable structure through which optional training programs take on an official and formal status. More specifically, supervisors are responsible for informing schools about the design and implementation of school activities, supporting and monitoring all the relevant programs of the school units in their area, and providing every possible help for their better implementation and quality. According to the circular of the Ministry of Education, the supervisors inform the head teachers and school teachers' Association, either by visiting schools or by having meetings with groups of teachers or individual teachers and head teachers, to inform about the possibilities of implementing school curricula in accordance with the relevant provisions and circulars of the competent bodies of the Ministry of Education and Religious Affairs. In any case, the school supervisor supports the teachers throughout the program. At the end of each school year, the supervisors write and send activity reports to the Education Directorates, the Regional Education Directorates, and the competent directorate of the Ministry of Health and Social Protection, where they also report their own suggestions and remarks on the implementation of specific training programs in their area.

It is evident that through the mandate defined, the school counselor, as an external school advisor, promotes the educational policy outlined by the central government, thus supporting the implementation of the introduced educational innovations. In particular, teachers are clear about the content and principles governing the philosophy of educational innovation. The school counselors monitor its implementation in practice, identify weaknesses, and intervene by proposing solutions. They encourage teachers to resort to new teaching methods and modern educational tools [39]. The work of the school counselor is not limited to just offering all kind of support to teachers, but requires appropriate management on the part of the multiple and different perceptions, knowledge, positions, and teachers' tendencies for shaping a school culture that favors innovative actions [40].

\subsection{Difficulties Impeding the Implementation of Flexible Zone Programs}

Rogers (1999) [41] reports that teachers pose barriers stemming from the situation in which they are, from the nature of educational programs and their personalities (factors of primary importance), and psychological and preexisting perceptions (internal barriers). They also adhere to the prevailing positions that provide them with certainty and security, preserving them as a sign of respect for their past professional career. Their well-established personal perceptions are expressed through their speech and actions [42] on teaching approaches and evaluation issues [43,44] while promoting a teaching process with new teaching methods and tools [45,46]. Barkatsas (1998) [47] states the teachers' overloading of work as the most common causes of failure of educational innovations, as they are constantly bombarded with continuous innovations and fragmented reform efforts into uncoordinated individual actions.

F.Z. is a centrally planned educational reformation with strong political will which is not to be left to chance after the necessary actions have been taken, something that educators, managers, parents, and students were informed about as a guarantee for success [48]. In the initial phase of innovation, the teachers' view is positive and favorable, as Kavouris (1999) [49] states, and is reinforced by the conclusion of Karatzia-Stavlioti and Alachiotis (2007) [50]. From the research carried out by the PI (2002) [51] for the pilot implementation of F.Z., the image obtained is positive as the goals of the F.Z. program are achieved. However, the ideally presented picture in the application of F.Z. is overturned, since it does not find the expected response from teachers who do not apply the F.Z. or apply it in their own way, which is incompatible with the instructions of the Analytical Curriculum [52].

In order to obtain a holistic view of the implementation of the F.Z. programs, the difficulties faced at the local level according to the literature must be discussed. Among the teachers' views, the main obstacles to the implementation of the F.Z. include inadequate training for appropriate targeting, active learning methods, team-dynamics, existing educational material, and program evaluation [53]. Moreover, obstacles include the lack of financial resources, the search for educational material, the cooperation with the school head teacher, the negative attitude of colleagues and school 
management [54], the lack of teachers' willingness, and the need to cover basic curriculum [55] due to the possibility of F.Z. using up time. Papanaoum's research (1998) [56] concluded that the lack of incentives for teachers, the inelasticity of the ACs, and the lack of manuals on environmental issues are inhibiting the implementation of programs.

Giannakaki's research (2000) [57] focuses more on the weaknesses of the school construct, like in the current institutional framework, and states there is a need for decentralization, which is favorable to the cooperation of a school with other institutions.

Many teachers do not respond to F.Z.'s educational change because there is insufficient support and also a lack of communication and cooperation between them beyond the school boundaries; they also believe that responsibility for the abovementioned lies with the school counselor of the region [58].

In an alarming finding, both Golfinopoulou and Kaldi (2007) [59] and Patsalis and Papoutsaki (2011) [21] have concluded that a large number of teachers do not apply the F.Z. or apply it by turning it into a formal process. They point out, as the most important reasons against its application, as the lack of time to cover basic subject curriculum (Greek and Mathematics), the stress of covering other subject curriculum, the lack of logistical infrastructure, the inability to find financial resources and the incomplete or inadequate training [60]. This results in the collapse of the ambitious program of the F.Z. under the responsibility of the teachers and the state [61].

The findings of Manesis, Katsaounos, and Tseregounis' (2006) [62] research are very important. In search of reasons that indicate a distance between the ministry's positions and the way in which the innovations are implemented, the study concludes that the security of everyday work leads teachers not to be disturbed and at the same time closing their own and their classes' doors to their colleague, the head teacher, and the school counselor.

\subsection{Overcoming Difficulties in Implementing the F.Z. Program}

In order to address the difficulties in the implementation of F.Z., Makri-Botsari (2007) [63] indicates that it is an important parameter to educate teachers on the placement and methodological approach of the programs. It appears that the teacher training seminars from school counselors and other educators contributed to emphasizing the need for intensified teacher support and the provision of interpersonal-personalized communication and personalized advice [51].

Spyropoulou, Anastasaki, Deligianni, Koutra, Louka, and Bouras (2007) [60] emphasize the need for motivation, presentation, and interdisciplinary and cross-curricular promotion of programs, as well as the necessary cooperation and trust among teachers, school counselors and supervisors responsible for school activities and, finally, the need to finance these actions.

Furthermore, in Mitakos' research (2006) [64], special mention is made of the technical skills that teachers should have for the course of a project, as an important component in the implementation of the F.Z. Thoonen, Sleegers, Ootr, and Peetsma (2012) [65] have also shown that improving the quality of school leadership is reflected in skill building for improved and more efficient schooling [66].

At this point, it is also necessary to make known the views of school counselors who consider that a large percentage of teachers are using the innovation of F.Z., but its implementation can be improved. According to the Baris, Papadimitropoulou, and Adamopoulou's (2013) [67] survey, in which the annual reports of twenty-four school counselors were submitted to the Institute for Educational Policy, revealed that school counselors are aware of the factors that make it difficult for the F.Z. to be implemented. They proposed continuous training, support of the utilization of F.Z. and proper planning and implementation of work plans, emotional support and dissemination of the results of F.Z., with teaching multipliers and the creation of electronic databases.

In addition, the work of school counselors in support of teachers could be helped by supervisors responsible for school activities and by each educational faculty [68]. Remarkable and interesting programs can result from the collaboration and synergy of school counselors and school supervisors [69]. 


\section{Materials and Methods}

\subsection{Research Objectives}

The purpose of the survey was to illustrate the teachers' views on the introduction of the innovative Flexible Zone program and the cross-curricular innovative programs implemented within it and to explore the role of school head teacher, school counselor and supervisor responsible for school activities in their implementation.

The research questions were:

(1) Why do teachers implement the Flexible Zone programs systematically or in a fragmented way?

(2) Why do teachers not implement Flexible Zone programs at all?

(3) What are the teachers' preferences regarding the subject, the teaching/support material used, the teaching method and the duration of the Flexible Zone programs?

(4) What is the role of educational head teacher, school counselor, or supervisor responsible for school activities, in implementing-or not-of the Flexible Zone according to the teachers' opinion?

(5) What difficulties do teachers encounter when implementing the Flexible Zone program?

(6) What are the teachers' suggestions for eliminating the difficulties of implementing the Flexible Zone programs more effectively?

In order to approach the subject of this research, quantitative research was chosen, where, through the action of the investigated subjects, it aimed to interpret what was happening at a specific time and place [70]. It was consistent with the given subject, as there were theoretical approaches with regard to the teachers and school unit managers' roles in introducing innovation and can be confirmed or toppled by empirical data [71].

In the present survey, the sample is composed of teachers who served in the district of Ilia in the school year 2016-2017. In total, there were 748 teachers (permanent and deputy); a representative sample because the selected individuals are a scaled down model of the educational sector.

In this case, questionnaires were sent to 250 teachers in order to collect at least 150 completed questionnaires, but 135 were collected as the final sample. This is a sample-collecting project, which, by handing out questionnaires to a small number of participants, highlights and generalizes trends, attitudes, opinions, values, beliefs, and behaviors of a large number of people [71,72].

\subsection{Demographics}

The sample of our survey consisted of 135 teachers: 84 women $(62.2 \%)$ and 51 men $(37.8 \%)$. Demographics clearly outline the profile of teachers. They have permanent positions, most are female, aged 41 and over, with more than 21 years of experience, and are graduates of the Pedagogical Academy and Primary Education Departments without further training or postgraduate studies. In addition to basic education, an overwhelming proportion of teachers (62.9\%) have not received F.Z.-related training. Of those who have been educated about F.Z. (37.04\%) it is mainly due to the school counselor, the Regional Training Centers, the school head teacher, and finally to the PI which amounted to an insignificant percentage.

\subsection{Data Collection Tool-Questionnaire}

The questionnaire of the survey includes twenty-eight closed-ended questions formulated by the study of questionnaires from other surveys on a related topic. Parallel discussions/meetings were arranged in the form of pilot interviews with specialists who have knowledge about the topic, namely four school head teachers, two school counselors, and the supervisor responsible for school activities to give their opinion regarding their actions to improve implementation of F.Z. by teachers. Before getting the final form of the questionnaire, pilot testing was conducted, in other words it was taken by six teachers and corresponding changes resulted based on their feedback. 


\subsection{Data Analysis}

After the questionnaires were collected, all 135 were numbered in increasing order and the answers were coded in numerical form and recorded in an Excel file. The SPSS program was used for the statistical analysis. More specifically, for each of the 28 questions of the survey questionnaire, a variable was constructed, while for questions with multiple answers (multiple-response sets), one variable per answer-choice was created, followed by the recording of SPSS responses.

Subsequently, a correlation test of the independent variables concerning (a) gender and (b) follow up on the implementation of the Flexible Zone was carried out, with the dependent variables of the first three research questions. More specifically, the Chi-Square test and the Mann-Whitney U statistical test of individual samples were used.

Moreover, with regard to the evaluation of the validity of the measurement scales in this questionnaire, a range of equal intervals, the known Likert scale, was used to ensure equal distances between the selected answers so that respondents can rate their answers from "never" to "always" [71].

\section{Results}

\subsection{Reasons Why Teachers Do or Do Not Implement Flexible Zone Programs}

The percentages refer to the total sample.

Out of the 135 valid responses recorded, it was found that 49 teachers $(36.3 \%)$ replied that they had "Sometimes" implemented it, 51 teachers (37.8\%) "Often" to "Continuously", while 45 teachers $(25.9 \%)$ from "Rarely" to "Never". In particular, in the last three school years, 24 teachers (17.8\%) implemented 4 programs, 24 teachers none, 23 teachers $(17.0 \%)$ implemented 3 programs, while 20 teachers $(14.8 \%)$ 6 programs or more.

By correlating the independent variables (the gender of the respondents and the follow-up of the training in the F.Z. application) with the dependent variables, it shows that:

- There is a correlation between teachers' gender with the frequency of implementation of Flexible Zone programs, with women more often implementing F.Z. programs than men.

- There is a correlation between the follow-up training for the implementation of F.Z. with the frequency of implementation of Flexible Zone programs. Those who have attended a training program more often implement flexible zone programs than those who have not attended.

- There is a correlation of the follow-up training for the implementation of the F.Z. with the number of Flexible Zone programs implemented over the last three years, with those who have attended a training program likely to implement more Flexible Zone programs than those who have not attended.

Referring to the responses of those who have implemented F.Z. programs, the majority implement them by assuming the obligation imposed by the central education authority and also for other reasons, personal, professional, or student-related. Regarding personal reasons, the alternative way of approaching knowledge, the expression of creativity in teaching, and the escape from the classroom routine stand out. As for professional reasons, the increase in school efficiency combined with the opening of the school to society and the development of collegial solidarity and cooperation seem to be the strongest ones. Regarding the reasons concerning students, teachers believe that F.Z. acts as an aid to participatory processes, knowledge acquisition, and the development of critical thinking, interests, and friendly relations.

There is an association between genders with the view that the Flexible Zone programs help:

1. Reducing the aggressive behavior of students, with women supporting this view more strongly than men.

2. Widening the interests of students, with women supporting this view more strongly than men. In addition, another view of this implementation of F.Z. emerges as the teachers' duty towards the ministry. 


\subsection{Teachers' Preferences in Implementing the Flexible Zone Programs}

The recorded teachers' preferences (between the official, the unofficial, and the two forms of implementation of F.Z.) state that $42.1 \%$ of the teachers choose the unofficial one and at the same time $49.1 \%$ chose both forms and only $8.8 \%$ chose the official one (by informing the school counselor and the school activities supervisor). Regarding the didactic method of the F.Z., there is a balance between the interdisciplinary and student-centered methods while the teacher-centered method is lacking.

In addition, $35.1 \%$ disregard the existence of support material, specific for the implementation of the F.Z. Most teachers state their preference firstly for long-term programs, then short-term programs, and finally medium-term programs. Finally, it is noted that the subjects of the F.Z. programs vary. From the correlation test of the independent variables (the gender of the respondents and the follow-up of the training for the application of F.Z.) to the dependent variables of the second research question, it emerged that:

- There is a gender association with the frequency of the use of the interdisciplinary method (project), with women using it more often than men.

- There is a correlation between teacher training for the implementation of F.Z. and the frequency of use of the teacher-centered method, with teachers who have not been trained to apply F.Z., using it more frequently than those who have undergone some training.

- There is a correlation between the follow-up training for the implementation of the F.Z. by using the basic educational material/cultural programs, and those who have attended a training program using it more in relation to those who have not attended.

- There is a correlation between the follow-up training for the implementation of the F.Z. and dealing with environmental issues. Teachers who have attended a training program generally deal with environmental issues more often than those who have not attended.

\subsection{Difficulties in Implementing the Flexible Zone Program}

Focusing on the difficulties in the implementation of F.Z., 113 valid answers were recorded. The majority of teachers $(81.4 \%)$ responded to having faced difficulties, while 21 teachers $(18.6 \%)$ responded negatively. More specifically, 57 teachers (62\%) opted for the lack of financial resources, 52 teachers $(56.5 \%)$ the extended basic subjects curriculum (Language, Mathematics), 46 teachers (50\%) the lack of logistical infrastructure, while 44 teachers $(47.8 \%)$ referred to the lack of time and lack of specialized knowledge concerning the F.Z.

On the other hand, only 20 teachers (21.7\%) opted for the ignorance of the use of new technologies, 25 teachers $(27.2 \%)$ the time-consuming programming required by extracurricular visits, 27 teachers (29.3\%) the lack of pedagogical guidance and 28 teachers (30.4\%) the negative attitude of the school's management towards the F.Z. The relatively few (22 teachers) who responded that they do not apply F.Z. programs at all stated the lack of cooperation and support by the supervisor responsible for school activities, the school counselor and teachers' association as the most important reasons.

\subsection{Teachers' Views on the Role of School Head Teacher, School Counselor and School Supervisor in Implementing or Not the Flexible Zone Programs}

By grouping the teachers' answers, the following emerged with regard to the school head teachers:

- teachers in a percentage of $70 \%$ recognize the efforts of the head teacher and the importance of his or her role in achieving cooperation and teamwork.

- $91.2 \%$ acknowledge the efforts of the school head teacher to manage the disputes arising from the implementation of work plans in the F.Z. program.

- $54 \%$ consider that the head teachers do not take a particularly active role in guidance and counseling for the school's teachers,

- $55.1 \%$ consider that head teachers do not assume as much of an energetic role as they should, regarding the linking of the F.Z. programs with the bodies of the local community 
- $\quad 65.5 \%$ believe that the school head teachers do not ask questions about the implementation of F.Z. programs to the Teachers' Association as much as necessary.

- $58.4 \%$ consider that head teachers do not provide the expected moral reward to teachers implementing F.Z. programs.

- $69.9 \%$ believe that head teachers do not act as much as they should for the in-school training of teachers on issues related to the implementation of F.Z. programs.

- $58.4 \%$ acknowledge the effort of the school head teacher to have the necessary logistic infrastructure to implement F.Z. programs.

As far as the school counselor is concerned:

- $89.4 \%$ of teachers acknowledge the interest of the school counselor to be informed about the work plans implemented by the teachers within the framework of the F.Z. programs.

- $67.3 \%$ believe that the school counselor conducts several training sessions/meetings that are related to F.Z. programs.

- $8.8 \%$ believe that there is a complete lack of co-operation between teachers and school counselors for the implementation of F.Z. programs.

Finally, with regard to the supervisor responsible for school activities, the following are observed:

- $72.5 \%$ of teachers believe that the school activities supervisor does not make as many visits as they would like, in the schools that implement actions related to the F.Z. programs.

- $69.9 \%$ believe that the school activities supervisor does not organize, as often as they would like, presentations of implemented actions that are included in the F.Z. programs.

- $15.9 \%$ consider that there is a complete lack of co-operation between teachers and school activities supervisors with respect to the implementation of F.Z. programs.

\subsection{Teachers' Suggestions for More Effective Implementation of F.Z. Programs with the Contribution of Educational Faculty}

The teachers' need to provide more regular, meaningful, and comprehensive information on F.Z. programs through in-school seminars and training sessions is solidified. What is more, on the part of head teachers, school counselors, the school activities supervisors, through the recording of teachers' views on the difficulties encountered, the practical requirements of teachers' demands for modernization of school equipment and cooperation at school level need to be addressed.

\section{Discussion}

It seems reasonable for the sample to be made up of more women aged 41 and older with over 21 years of working experience since the education sector is female-dominated and the age data proves the absence of recruitment of new teachers. As Brinia (2012) [73] indicates, women are intrigued by the social characteristics of their work and, as a result, they really enjoy working with children. At the same time, the specific sample being called to answer, works in six-year and larger, organic elementary schools in urban centers where the posts are occupied by older ones in service. The overwhelming fraction of teachers $(62.9 \%)$ who have not received F.Z.-related training is considered a major omission by the state support mechanism for innovation.

The frequency rates for the implementation of F.Z. programs show the positive response of the teachers of the Ilia district and their answers confirm the high percentage of embeddedness in the daily educational process reported by Kavouris (1999) [49], Karatzia-Stavlioti, and Alachiotis (2007) [50]. However, there is a significant percentage (25.9\%) in the "never" and "rarely" answers found by Golfinopoulou and Kaldi (2007) [59] and Patsalis and Papoutsaki (2011) [21]. The recorded rates of research show there is an equal distribution between those applying Flexible Zone programs almost every school year, those who apply it at a moderate frequency, and those who are not at all involved with it. 
The findings regarding the gender correlation of respondents and the follow-up of F.Z. training with the frequency of implementation of Flexible Zone programs, with women implementing F.Z. programs more often than men, is logical, since the majority of the survey subjects are women [73]. However, also in Patsalis and Papoutsaki's survey (2011) [21], it is confirmed that the percentage of women outweighs the percentage of men in the application of F.Z. programs. The same stable finding is also shown in the Gianniris' survey (2012) [74].

The answers of those who have implemented F.Z. programs for other reasons, either personal or professional, or student-related reasons as found by the research by Dimitriou and Zachariadou (2005) [75], are identical. Among the personal reasons, the alternative way of approaching knowledge, the expression of creativity in teaching, and the escape from the classroom routine stand out. Regarding professional reasons, they report a stronger increase in school efficiency combined with the opening of the school to society and the development of collegial solidarity and cooperation as Angelidou and Kritikou (2005) [76] found in their research. Regarding the reasons concerning students, teachers believe that F.Z. acts as an aid to participatory processes, the acquisition of knowledge, and the development of critical thinking, interests, and friendly relations. The same reasons have been identified by Stergiou (2003) [77] and Gianniris (2012) [75]. The detection of gender correlation to the view that the F.Z. programs help to broaden students' interests, with women supporting this view more than men, is not supported by the findings of Patsalis, Papoutaki and Zouganeli (2012) [78], since no correlation emerged.

Furthermore, another view of the implementation of F.Z. emerges as the teacher's duty towards the Ministry and more generally the supreme authority. Perhaps the teacher fears that the non-implementation of F.Z. programs will be interpreted as an irregularity, an oversight that will lead to some form of "punishment".

The relatively few in number teachers (22) who replied that they do not apply F.Z. programs at all reported as the most important reasons: the lack of cooperation, support from the school head teacher, the school counselor, and the teachers' association. It is worth noting that this interpretation concerns specific persons who hold positions of responsibility in the educational district that the prefecture of Ilia belongs to, whose actions and choices are perhaps considered misplaced and fruitless by the teachers. Also, in previous researches, there was not a percentage of teachers who did not apply F.Z. programs but rather a decrease in the percentage of participation in similar programs [53] or their application was far from their philosophy [23,52].

The recorded teachers' preferences indicate that of the teachers, between the official, the unofficial and the two forms of implementation of F.Z. programs, $42.1 \%$ avoided the official form and choose the unofficial, $49.1 \%$ of them avoided the two forms, and only $8.8 \%$ completed the special form, and through it the school counselor or the school head teacher were informed. At this point, a concern is raised regarding the choice of the teacher, since a divide between the educational and school counselor and the supervisor for school activities appeared, even though their institutional position was placed next to the teacher to provide assistance, support, and cooperation. Teachers' preferences on the teaching method demonstrated the professionalism of modern educators who adopt new trends in teaching, psychology, and education sciences and are informed without remaining rigid and clinging to the past. The finding of our research is identified by the findings of the research of Dimitriou and Zachariadou (2005), [75], which presents the most important method for the implementation of the E.E programs, the project method. However, this finding is in contrast to the findings of Patsalis and Papoutsaki (2011) [21], which show a small percentage of teachers to prefer the interdisciplinary approach. Besides, it is not possible to excommunicate the older teaching methods because of what they may offer at the right time, to the appropriate student community and because are difficult to avoid altogether [79].

In addition, 35.1\% disregard the existence of support material specific for the implementation of the F.Z. programs. This raises the question whether a similar effort has been made to bring teachers into contact with the publication of the region of Western Greece for F.Z. programs, since only 15 
teachers use it. Perhaps this shows that this handbook has not been promoted by the supervisor as much as they should have to become the educational initiators of the whole effort.

The result of the choice of long-term programs has a double interpretation, on one hand it shows that teachers are not afraid to dive in and analyze a subject of F.Z. for study; on the other hand, perhaps this indicates that they waste time throughout the school year, never completing the program.

Finally, it is noted that the subjects of the F.Z. programs vary and that teachers prefer these varied themes, such as environmental issues as mentioned in Papadimitriou's (1995) [80] research, health education issues, cultural issues, and issues from school textbooks. The hierarchy of the themes of the programs implemented within the framework of the F.Z. is similar to the findings of the study by Spyropoulou et al. (2008). As a result, there is a correlation between the follow-up of the training for the implementation of F.Z. programs and the environmental issues; with teachers who have attended a training program likely to be more concerned with environmental issues than those who have not attended [69]. This finding focuses on teachers' interest in environmental issues, and is justified as our country is being hit by ecological disaster, having also taken into account the contribution of Centers for Environmental Education.

There is a correlation between the training of teachers for the implementation of F.Z. and the frequency of use of the teacher-centered method, with the teachers who have not undergone training for the application of F.Z. programs being likely to use it more frequently than those who have undergone some training. This finding is quite reasonable, as teachers who have not been trained to implement F.Z. programs and the process of a project feel unprepared to implement a work plan in practice and resort to their trusted method, the teacher-centered method. In this approach, the teacher assumes the role of the supreme educational authority in the classroom, expecting the students to simply listen to them unconditionally, rarely encouraging interaction. The very nature of the Flexible Zone program, however, encourages the students themselves to get involved in the teaching process through discussions and group projects. Through these, students become more autonomous and independent in the way they learn, by being able to research topics on their own and conduct educational and informative conversations with teachers, and as a result they have access to legitimate and trusted sources within a supervised environment. Thus, the focus and responsibility of the education is split between the teacher and the student and in turn makes the whole learning experience shift greatly toward the student-centered method, rather than the traditional teacher-centered one.

The inhibiting factors that make it difficult to implement programs are also reported in other surveys. In particular, the great amount of curriculum to be taught by teachers and consequently the use of F.Z.'s time is mentioned as the primary difficulty in applying F.Z. according to the research of Patsalis, Papoutsaki, and Zouganeli (2012) [78]. Moreover, in the research by Spyropoulou et al. (2007) and in the research by Dimitriou and Zachariadou (2005) [75], the lack of adequate logistic infrastructure, inadequate funding, and inadequate teacher education are mentioned as the most important factors that make it difficult to implement programs. It seems that three inhibitory factors for the application of F.Z. are identical in both surveys with the findings of our research. The lack of sufficient training and the lack of organization and cooperation among teachers are mentioned by Spyropoulou (2001b) [53], and the teachers' work outside the school hours added by Papageorgiou and Tsinas (2010) [23], which highlight the incomplete support of the school counselor and the difficulties in co-operation between teachers. Fouseki's (2005) [54] research confirms these findings with regard to the need for additional training, but adds as obstacles the great amount of preparation it needs, the lack of interest from the students, and the negative attitude of the school management and colleagues. Among the reported difficulties in the implementation of F.Z., the reluctance of co-teachers to co-operate is a problematic point and contradicts the philosophy of F.Z. which aims to open the school to society and which will only be achieved when the teachers open the door of their class to the fellow teachers and exchange views and ideas. 
The findings of our research are not identical with the findings of Giannakaki's research (2000) [57] which identifies the lack of decentralization due to the existing institutional framework and the need for cooperation between the participating institutions and factors as deterrents.

We noticed that the school head teachers were trying to stand by the teachers, to work supportively, to assist, but in particular, the head teachers' actions were lagging behind at several levels. The head teachers' profile was not that of the transforming leader [35], a qualitative leader [66] who can also handle business issues, human relations issues, and their attitude to effectively influence their associate teachers. It seems that the head teachers try, but the findings do not outline the profile of a head teacher that comes close to a leader who is aligned with the principles of a participatory way of administration. The head teachers' decisions should encompass the consensus of the majority and be taken jointly. Regarding the actions of the school counselors, some found them satisfactory, such as their availability for information on the F.Z. programs, but their cooperative availability was not sufficient to organize training sessions. This finding is interpreted as the large number of schools that each school counselor has in his/her supervision and the great distances between schools, which lead to the absence of direct contact and organization of in-school teacher education. However, some of the distinct elements a professional counselor should possess are a keen interest in teachers, desire for personal work, offering knowledge and help, and presenting work plans, as mentioned in the research by Vergis, Papadopoulou, and Chalkiadaki (2006) [81].

Summarizing, teachers mention that they are not satisfied with the support provided by the school head teacher and are the most challenged in relation to other educational staff.

It is alarming to find that teachers $(16.8 \%)$ consider that there is a complete lack of co-operation between teachers, school counselors, and school activities supervisors in the implementation of F.Z. programs. This percentage is slightly higher (about $1 \%$ ) compared to the corresponding percentage about working with the school counselor. This cooperation has also been highlighted as a guarantee for the production of remarkable programs like F.Z. [69]. Our findings are completely different from the finding of the research conducted by the PI (2002) [51] and Brinia, Ziminiati, and Panagiotopoulos (2014) [82] which states that there is a very good environment of co-operation between teachers, head teachers, and school counselors.

In conclusion, there are signs that training staff fully responded to some of their obligations, but their efforts were insufficient and shortcomings are noted, as reported by West-Burnham (1991) [22] and Karabelas, Kelly, and Fokiadi (2006) [58].

Through the views of teachers, Yfanti (2000) [48] discusses the necessary educational and informative actions that must be taken throughout the professional career of a teacher, with various topics such as the application of F.Z. However, this does not seem to be the case within the systematic and repetitive rhythm in the Greek educational reality. At this point, the personal responsibility of teachers for their training in the implementation of F.Z. may be shifted to the responsibility of educational executives, as Manesis, Katsaounos, and Tserengounis (2006) [62] have explored. From the answers to the above-mentioned research it appears that inadequate training is one of the main reasons teachers are accustomed to a given way of work and do not change it by incorporating educational innovations.

The need for teachers to be provided with more regular, meaningful, and comprehensive information about the F.Z. by in-school seminars and training sessions have been highlighted by Baris, Papadimitriou, and Adamopoulou (2013) [67]. On the part of the head teacher, school counselor, and the school activities supervisor, recording the views of teachers on the difficulties they face at a practical level and the teachers' demand for modernization of school equipment and cooperation at a school level have also been highlighted in the research mentioned above. Regarding the school counselor's role, our findings agree with Vergis, Papadopoulou, and Chalkiadaki's research (2006) [81] which indicates the desire of teachers for a school counselor distinguished by professionalism who shows interest and continually updates teachers. 
In her article, on the implementation of the F.Z. programs, Galanopoulou (2002) [68] presents the final evaluation report for the first year of 2001-2002 application of the F.Z. programs. It is important to note that F.Z. programs need to be framed by the school counselors who could be helped by school activities supervisor as anyone can support schools with their own useful contribution. Also, in the research of Patsali and Papoutsaki (2011) [21] and Gianniris (2012) [74], teachers propose training on how to apply F.Z., help, and support from the school counselor, findings that have emerged from our research as well. Contrary to the findings of our research, the findings of Patsalis, Papoutsaki, and Zouganeli's (2012) [78] research indicate that teachers' suggestions for better implementation of F.Z. programs focus exclusively on financial support from the ministry for program development, reduction of the Greek and Mathematics curriculum, and the creation of appropriate logistical infrastructure in schools. The fact that many schools lack the necessary infrastructure and tools for a more complete and correct implementation of the F.Z. programs leads students to enroll in extra-curricular activities outside the school environment. With the correct resources, the F.Z. can accommodate many of these activities and subjects, so that students will be able to focus on them within the supervised environment of the school and integrate them as a part of the whole educational experience. Such innovative learning spaces can include dedicated sports facilities, interactive classrooms, multimedia rooms for viewings, classrooms dedicated to art, etc. As for outdoor learning places, the F.Z. can include outside classes, nature walks, and cultural promenades according to Brinia, Psoni, and Ntantasiou (2019), and visits to various places of interest like museums and ancient sites [83].

\section{Limitations of Present Study and Suggestions for Future Research}

Throughout this research process, it is worth mentioning we encountered great difficulty with the relative indifference from fellow teachers to complete the questionnaire and thus the aim of collecting about 150 questionnaires was not achieved and only 135 were gathered, despite 250 having been handed out.

In addition, the time constraint only led to the use of the questionnaire as a research tool and not in conjunction with other research tools, data collection methods, i.e., a multidisciplinary approach, called triangulation [84].

This research provides a substantial basis for the continuation of research on related issues with F.Z. and the role of educators in its more effective implementation. The findings of the survey conducted could not be generalized for the implementation of the F.Z. programs and the role of educational staff for the whole of Greece, as the teachers' views were gathered only from the district of Ilia. This limited possibility of generalizing the findings of the survey could be lifted by conducting research in other districts of Greece. However, the present paper refers to Flexible Zone programs, which constitute a better teaching practice that certainly can provide the policy makers worldwide with valuable information about their implementation.

In addition, other independent variables other than gender, years of service, training, other qualifications and the number of seminars they have attended on F.Z., such as the school headquarters (urban, semi-urban, rural) and type of school (public, private), can be used. The same goes for dependent variables, in particular factors that either encourage or prevent teachers from implementing the F.Z. These will minimize the possibility of generalizing misconceptions.

It would also be ideal to combine qualitative and quantitative research forms, in other words a multi-method research approach to the subject in addition to quantitative research with a research tool, the questionnaire.

\section{Conclusions}

The given research not only seeks to update the data of other similar past researches but also seeks to provide a driving force for a thorough and multifaceted study of the subject under consideration. The main goal is to respond to contradictory point-problems that arise in the process between the design of the central authority in the legislative establishment and implementation of the school's innovative 
F.Z. program. According to the abovementioned analysis, the international readership, by getting invaluable information about the Greek example regarding innovative programs' implementation may be provided with in-depth suggestions for modifications, revisions, or changes to the subsequent educational policy for the introduction of innovative programs at schools worldwide. In addition, teachers and educational staff involved (school head teachers and school activities supervisors) will be brought feedback by doing their self-criticism. There is no reference to the school counselor, as in the face of the imminent changes, the school counselor role has been abolished and perhaps a discussion about the necessity of having positions such as this may have to begin.

Using the extracted results, discussion at the level of the State can be considered in order to review the role of the school supervisor and school principal and how they are selected and placed where necessary, in order to establish substantive criteria for selecting people with a meaningful and original role.

This kind of innovative intervention can be implemented worldwide in order to offer valuable educational support to students and the whole educational process in general. Such support can be in the form of officially-allocated school hours, teaching resources and equipment, and lists of potentially interesting subjects to focus on. As a result, students will have the opportunity to explore and study various subjects, which in the eyes of many, constitute indispensable skills and necessary knowledge in today's rapidly evolving society. Such matters can be of a technological, environmental, social, and even artistic nature. This extends far beyond Greece, as the subjects examined by programs similar to F.Z. (such as the "Exploratory Classes" in the Secondary Education) are very much global and closely follow the progress of the collective society of the entire world.

Author Contributions: Conceptualization, V.B. and V.-N.S.; methodology, V.-N.S.; software, V.-N.S.; validation, V.B., V.-N.S.; formal analysis, V.B. and V.-N.S.; investigation, V.B. and V.-N.S.; resources, V.B.; data curation, V.-N.S.; writing - original draft preparation, V.B. and V.-N.S.; writing—review and editing, V.B.; visualization, V.-N.S.; supervision, V.B.; project administration, V.B.

Funding: This research received no external funding.

Conflicts of Interest: The authors declare no conflict of interest. The funders had no role in the design of the study; in the collection, analyses, or interpretation of data; in the writing of the manuscript, or in the decision to publish the results.

\section{References}

1. McNeil, J. Curriculum: A Comprechensive Introduction; Harper Collins: New York, NY, USA, 1996.

2. Fullan, M.G. The Meaning of Education Change; Cussell: London, UK, 1991.

3. Fullan, M.G. The management of change. In The Management of Schools; Mcmahon, E.H., Ed.; Kogan Page: London, UK, 1986; pp. 73-85.

4. Papakonstantinou, G. Educational Management: Neo-taylorism inclination in the Greek educational system. Adm. Brief. 2007, 41, 62-72. (In Greek)

5. Kirkland, K.; Sutch, D. Overcoming the Barriers to Educational Innovation: A Literature Review; Futurelab: Bristol, UK, 2009.

6. Fullan, M.G. Research into educational innovation. In Understanding School Management; Glatter, R., Preedy, M., Richers, C., Masterton, M., Eds.; Open University Press: London, UK, 1988; pp. 195-211.

7. Brinia, V.; Tsouni, V. Management and Leadership: Perceptions of principals and teachers of the Secondary Education Directorate. Int. J. Acad. Res. Progress. Educ. Dev. 2017, 6, 11-27. [CrossRef]

8. Watt, D. How Innovation Occurs in High Schools within the Network of Innovative Schools: The Four Pillars of Innovation Research Project. The Conference Board of Canada. Available online: http://www.schoolnet. ca/nisrei/e/research/pillars/index.asp (accessed on 20 March 2002).

9. Priestley, M.; Edwards, R.; Priestley, A.; Miller, K. Teacher agency in curriculum making agents of change and spaces for maneuver. Curric. Inq. 2012, 42, 191-214. [CrossRef]

10. Brinia, V.; Papantoniou, E. High school principals as leaders: Styles and sources of power. Int. J. Educ. Manag. 2016, 30, 520-535. [CrossRef] 
11. Sauve, I.; Goffin, L. Editorial pour une ERE reflexice. In Colloque International sur la Recherche en ERE, Education Relative a l' Environmemtal, Regards, Recherches, Reflexions, Montreal Novembre 1997; Fondation Universitaire Luxembourgeoise: Luxembourg, 2017; Volume 1, pp. 7-10.

12. Giolitto, P.; Clary, M. Profession Enseignant, Eduquer a L'environmental; Hachette: Paris, France, 1994.

13. Gough, A. Education and environmental: Policy, Trends and the problems of marginalization. Aust. Educ. Rev. 1997, 39, 23-35.

14. Hart, P. Rethinking teacher education environmentally. In Preparing Classroom Teachers to Be Enviromantal Educators; Engelson, D.C., Disinger, J.F., Eds.; The North American Association for Environmental Education: Troy, OH, USA, 1990; pp. 7-17.

15. Charlot, B.; Beillerot, J. La Construction des Politiques d' Education et de Formation; Pedagogied' Aujourdhui: Paris, France, 1995.

16. Matsagouras, E. Flexible Zone of the interdisciplinary approach: An educational innovation that changes school. Rev. Educ. Issues 2002, 6, 15-30. (In Greek)

17. Erickson, H.L. Concept-Based Curriculum and Instruction: Teaching Beyond the Facts; Corwin Press: Thousand Oaks, CA, USA, 1998.

18. English, G.J. The Exploratory Concept in Middle School Curriculum. Middle Sch. J. 1972, 3, 32-34. [CrossRef]

19. Wolk, S. The Benefits of Exploratory Time. Educ. Leadersh. 2001, 59, 56-59.

20. Koptsis, A. Basic principles of modern teaching and their application in the project methodology. Rev. Educ. Issues 2009, 15, 16-28. (In Greek)

21. Patsalis, C.; Papoutsaki, K. Flexible Zone, theory and practice. Rev. Educ. Issues 2011, 17, 144-154. (In Greek)

22. West- Burnham, J. Education Management for 1990s; Longman: Essay, UK, 1995.

23. Papageorgiou, G.; Tsinas, E. Staseis kai antilipseis ton ekpedeftikon tis 16th perifereias PE Athinon schetika me tin efarmogi tis Eveliktis Zonis. In Proceedings of the 5th Panhellenic Conference on "Mathaino pos na mathaino", Athens, Greece, 7-9 May 2010.

24. Frey, K. I Methodos Project [The Project Method]; Malliou, K., Translator; Kyriakidi: Thessaloniki, Greece, 1986.

25. Han, S.; Weiss, B. Sustainability of teacher implementation of school-based Mental health programs. J. Abnorm. Child Psychol. 2005, 33, 665-679. [CrossRef]

26. Beladakis, E. The education leaders' contribution to the successful implementation of educational innovations. Adm. Brief. 2010, 53, 103-111. (In Greek)

27. Rashid, K.; Hussain, M.; Nadeem, A. Leadership and innovation in a school culture: How can a leader bring about innovation in the school culture? J. Elem. Educ. 2011, 21, 67-75.

28. Click, P. Dioikisi Monadon Proscholikis kai Scholikis Agogis [Pre-School and School Education Units Management]; Spanou, M., Translator; Ekdosis Ellin: Athens, Greece, 2005.

29. Heller, R. The Decision Makers; Hodder and Stoughton: London, UK, 1989.

30. Everard, K.B.; Morris, G.; Wilson, I. Effective School Management; Chapman: London, UK, 2004.

31. Earley, P.; Fletcher-Campbell, F. The Time to Manage?: Department and Faculty Heads at Work; Nfer Nelson: Windsor, UK, 1989.

32. Hollander, E. Leadership and power. In The Handbookof Social Psychology; Lindzey, G., Aronson, E., Eds.; Random House: New York, NY, USA, 1985; pp. 485-537.

33. Brinia, V.; Perakaki, S. How interpersonal relations are affected by and affect the selection of head teachers in primary education: The teachers' perspectives. Int. J. Manag. Educ. 2018, 12, 332-350. [CrossRef]

34. Vroom, V.; Vetton, P. Leadership and Decision Making; University of Pittsburgh: Pittsburgh, PA, USA, 1973.

35. Hallinger, P. Leading educational change: Reflections of the practice of instructional and transformational leadership. Camb. J. Educ. 2003, 33, 329-351. [CrossRef]

36. Poo, B.; Hoyle, E. Teacher involvement in decision making in South Africa. In Bristol Papers in Education: Comparative and International Studies; University of Bristol: Bristol, UK, 1995; Volume 4, pp. 69-91.

37. Leithwood, K.; Harris, A.; Hopkins, D. Seven strong claims about successful school leadership. Sch. Leadersh. Manag. 2008, 28, 27-42. [CrossRef]

38. Hargreaves, D. School culture, school effectiveness and school improvement. Sch. Eff. Sch. Improv. 1995, 6, 23-46. [CrossRef]

39. Kouloumbaritsi, A.; Anastasaki, A.; Argyroudi, I.; Kalogerakos, N.; Papastergiopoulou, C.; Triantafyllopoulou, P.; Tsirikos, G. The Administrative Framework in Primary and Secondary Education. Rev. Educ. Issues 2007, 13, 42-51. (In Greek) 
40. Papaprokopiou, N.; Bakas, T. O rolos tou scholikou symvoulou sthn proothisi kai diadosi ton ekpaideftikon allagon. In Ekpedeftikes Allages, I Paremvasi tou Ekpedeftikou kai tou Scholeiou [Educational Changes, Teacher and School Intervention]; Bagakis, G., Ed.; Metaichmio: Athens, Greece, 2006; pp. 81-89.

41. Rogers, A. I Ekpedefsi Enilikon [Teaching Adults]; Papadopoulou, M.; Tombrou, M., Translators; Metaichmio: Athens, Greece, 1999.

42. Torf, B.; Sternberg, R.J. Understanding and Teaching the Intuitive Mind: Student and Teacher Learning; Lawrence Erlbaum: Mahwah, NJ, USA, 2000.

43. Robottom, I. Beyond behaviourism: Making EE research educational. In Alternative Paradigms in Environmental Education Research, Monographs in Environmental Education and Environmental Studies; Mrazek, R., Ed.; The North American Association for Environmental Education: Troy, OH, USA, 1993; Volume 8, pp. 133-143.

44. Hart, P. Teachers' ideas about environmental education. In Environmental Education for the Next Generation-Professional Development and Teacher Training; Abrams, R., Ed.; The North American Association for Environmental Education: Troy, OH, USA, 1997; pp. 184-188.

45. Leach, C. Managing Whole school change. In Development Education; Osler, A., Ed.; Cussell: New York, NY, USA, 1994.

46. Vandenberghe, R. School improvement from a European perspective. Qual. Stud. Educ. 1998, 1, 79-90. [CrossRef]

47. Barkatsas, A. Reasons for failure of innovative institutionalized reforms and proposals for their evaluation. Educational 1998, 47-48, 129-138. (In Greek)

48. Yfanti, A. Educational changes and school improvement. A multifaceted relationship. Mod. Educ. 2000, 113, 57-63. (In Greek)

49. Kavouris, P. The teachers and head teachers' perceptions in teaching and organizational innovations of the school. Mod. Educ. 1999, 106, 91-100. (In Greek)

50. Karatzia-Stavlioti, E.; Alachiotis, S. Evaluation of a cross-theamatic curricular innovation. Teachers' attitudes and the Flexible Zone (F.Z.). Int. J. Learn. 2007, 14, 267-275.

51. Pedagogical Institute. Evaluation of the Innovative Pilot Program of the Flexible Zone in Schools of Compulsory Education; Pedagogical Institute: Athens, Greece, 2002.

52. Polyzois, L.; Palapani, D. The Flexible Zone. Teach. Podium 2007, 1143, 34-35. (In Greek)

53. Spyropoulou, D. Assessment of environmental education in the 1991-2000 period. Rev. Educ. Issues 2001, 5, 155-164. (In Greek)

54. Fouseki, E. "Is" and "get" in environmental education programs. Empirical research and a testimony of experience. In Proceedings of the 1st Environmental Education Programs Conference, Isthmos Korinthos, Greece, 23-25 September 2005.

55. Spyropoulou, D. Environmental education under the Flexible Zone: Weather and climate-Protection of the atmosphere. Rev. Educ. Issues 2001, 6, 160-171. (In Greek)

56. Papanaoum, Z. Environment and education from the perspective of teachers: An empirical exploration. Pedag. Rev. 1998, 28, 171-193. (In Greek)

57. Giannakaki, M.S. Organization and policy of environmental education for sustainable development. Adm. Brief. 2000, 5, 120-126. (In Greek)

58. Karabelas, K.; Kelly, A.; Fokiali, P. I allilepidrasi kai h epikoinonia mesa sto scholiko choro os ousiodis proypothesi gia epityximeni kai viosimi ekpedeftiki allagi [Interaction and communication within the school space as an essential prerequisite for successful and sustainable educational change]. In Ekpedeftikes Allages, h Paremvasi tou Ekpedeftikou kai tou Scholeiou [Educational Changes, Teacher and School Intervention]; Bagakis, G., Ed.; Metaichmio: Athens, Greece, 2006; pp. 56-65.

59. Golfinopoulou, V.; Kaldi, S. Apopsis ekpedeftikon gia tin efarmogi tis diathematikotitas kai tis didaktikis methodou project stin protovathmia ekpedefsi [Teachers' views on the implementation of cross-curricular and project-based teaching in primary education]. In Proceedings of the 6th Protovathmia Ekpedefsi kai oi Proklisis tis Epochis mas Panhellenic Conference, Ioannina, Greece, 17-20 May 2007.

60. Spyropoulou, D.; Vavouraki, A.; Koutra, C.; Louka, E.; Bouras, S. Innovative programs in education. Rev. Educ. Issues 2007, 13, 69-83. (In Greek)

61. Patsalis, C. Flexible Zone of Cross-curricular and Creative Activities, a Challenge Innovation. New Educ. 2008, 129, 2-9. (In Greek) 
62. Manesis, N.; Katsaounos, E.; Tserengouni, A. Ekpedeftikes Allages, I Paremvasi tou Ekpedeftikou kai tou Scholeiou [Educational Changes, Teacher and School Intervention]; Bagakis, G., Ed.; Metaichmio: Athens, Greece, 2006; pp. 98-106.

63. Makri-Botsari, E. Themata Eisagogikis Epimorfosis gia Neodioristous Ekpedeftikous [Introduction to Vocational Training for Newly Appointed Teachers]; Pedagogical Institute: Athens, Greece, 2007.

64. Mitakos, D. I evelikti zoni os paragontas diamorfosis tis kritikis skepsis [The flexible zone as a factor in the formation of critical thinking]. In Proceedings of the 3rd HELL.I.A.P.ED Panhellenic Conference, Athens, Greece, 13-14 May 2005.

65. Thoonen, E.; Sleegers, F.; Oort, F.; Peetsma, T. Building school-wide capacity for improvement: The role of leadership, school organizational conditions, and teacher factors. Sch. Eff. Sch. Improv. 2012, 23, 441-460. [CrossRef]

66. Rhodes, C.; Brundrett, M. Leadership development and school improvement. Educ. Rev. 2004, 61, 361-374. [CrossRef]

67. Baris, T.; Papadimitropoulou, P.; Adamopoulou, A. I efarmogi tis Eveliktis Zonis sta dimotika scholeia tis Perifereias Dytikis Elladas [The implementation of the Flexible Zone in the primary schools of the Western Greece District]. In Proceedings of the 1st Panhellenic Union of School Counselors Conference, Korinthos, Greece, 23-24 November 2013.

68. Galanopoulou, D. The implementation of the Flexible Zone during the academic year 2001-2002. Rev. Educ. Issues 2002, 6, 271-285. (In Greek)

69. Spyropoulou, D.; Anastasaki, A.; Deligianni, D.; Koutra, C.; Louka, E.; Bouras, S. Ta kainotoma programmata stin protovathmia kai defterovathmia ekpedefsi: Leitourgiki dieisdytikotita kai viosimotita Innovative programs in primary and secondary education: Functional penetration and sustainability. In I poiothta stin ekpedefsi [Quality in Education]; Vlachos, D., Ed.; Pedagogical Institute: Athens, Greece, 2008; pp. 88-101.

70. Cohen, L.; Manion, L.; Morrison, K. The Methodology of Educational Research; Metaichmio: Athens, Greece, 2008.

71. Creswell, J. Educational Research: Planning, Conducting, and Evaluating Quantitative and Qualitative Research, 3rd ed.; Pearson Education, Inc.: Upper Saddle River, NJ, USA, 2008.

72. Robson, C. I Erevna tou Pragmatikou Kosmou. Ena meson gia Koinonikous Epistimones kai Epaggelmaties Erevnites [Real World Research: A Resource for Social Scientists and Practitioner-Researchers]; Dalakou, V.; Vasilikou, K., Translators; Gutenberg: Athens, Greece, 2010.

73. Brinia, V. Men vs women; educational leadership in primary schools in Greece: An empirical study. Int. J. Educ. Manag. 2012, 26, 175-191. [CrossRef]

74. Gianniris, K. Erevna gia ta 20 Chronia Perivallontikis Ekpedefsis [Research for the 20 Years of Environmental Education in Greece]. Available online: www.kpe.gr/proceedings/2_Educational_Research/75-Gianniris.pdf (accessed on 7 April 2018).

75. Dimitriou, A.; Zachariadou, E. Ekpedeftikoi kai perivallontiki ekpedefsi: To paradeigma ton ekpedeftikon pou ypiretoun se scholeia tis Protovathmias ekpedefsis sto Nomo Evrou [Educators and environmental education: The example of teachers serving in schools of primary education in the Evros District]. In Proceedings of the 1st Scholikon Programmaton Perivallontikis Ekpedefsis Conference, Isthmos Korinthos, Greece, 23-25 September 2005.

76. Angelidou, E.; Kritikou, E. Kinitra symmetoxis ton ekpedeftikon se programmata P.E. kai logoi diakopis tis symmetoxis tous [Teachers' incentives for their participation in E.E programs and reasons for discontinuing their participation]. In Proceedings of the 2nd Panhellenic Symposium: Empnefsi- Stochasmos-Fantasia, Piraeus, Greece, 1-2 April 2005.

77. Stergiou, V. Review of the programs of the First Bureau of Secondary Education in Kozani District. Pan-Hell. Assoc. Educ. Environ. Educ. 2003, 29, 15-19. (In Greek)

78. Patsalis, C.; Papoutsaki, K.; Zouganeli, A. I efarmogi tis Eveliktis Zonis se oligothesia scholeia [The implementation of the Flexible Zone in multigrade schools]. In Proceedings of the Pedagogical Department of Athens Conference on I Poiotita stin Ekpedefsi: Taseis kai Prooptikes, Athens, Greece, 11-13 May 2012.

79. Gouvra, M.; Kyridis, A.; Mavrikaki, E. Agogi Ygeias kai Scholeio [Health Education and School]; Gutenberg: Athens, Greece, 2003.

80. Papadimitriou, V. Teachers and Environmental Education. Pedag. Rev. 1995, 22, 215-231. (In Greek) 
81. Vergis, A.; Papadopoulou, A.; Chalkiadaki, A. Evelikti Zoni: To anekpliroto oniro, [Flexible Zone: The unfulfilled dream] In Ekpedeftikes allages, I paremvasi tou ekpedeftikou kai tou scholeiou [Educational changes, school and teacher's intervention]. In Proceedings of the 7th Annual Monadas Methodologias kai Programmaton Ekpaidefsis Conference of DESECE, Patras, Greece, 10-12 April 2005; Metaichmio: Athens, Greece, 2006; pp. 238-246.

82. Brinia, V.; Ziminiati, L.; Panagiotopoulos, K. The Role of the Principal's Emotional Intelligence in Primary Education Leadership. Educ. Manag. Adm. Leadersh. 2014, 42, 28-44. [CrossRef]

83. Brinia, V.; Psoni, P.; Ntantasiou, E.K. How to Instill Cultural Values in the New Generation through Cultural Promenades and Ancient Drama: A Field Research. Sustainability 2019, 11, 1758. [CrossRef]

84. Vergidis, D. Polymethodiki kai diepistimoniki dierevnisi ton ekpedeftikon anagon [Multimethodical and interdisciplinary investigation of the educational needs]. In Isagogi Stin Ekpedefsi Enilikon. Schediasmos, Organosi kai Axiologisi Programmaton [Introduction to Adult Education. Program Planning, Organization and Assessment]; Kokkos, A., Ed.; HOU: Patras, Greece, 2008; Volume 3, pp. 38-42.

(C) 2019 by the authors. Licensee MDPI, Basel, Switzerland. This article is an open access article distributed under the terms and conditions of the Creative Commons Attribution (CC BY) license (http://creativecommons.org/licenses/by/4.0/). 